NUUH I U ᄃ A $U$ U

$U \cup D M P O D T H M G R \times B D P B L R \cup Z T R\llcorner v v \backsim$

UAOBN IMIKOQAYLARNLDBEUBAFVNK,

A A MOA L T E R N A T I N G R T O R Q U E L S E R N G M J b, ,

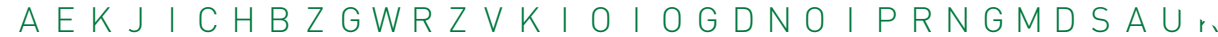

EMOTMVTI LQNVXDOMGMNESWLNCAWZYKFEQLO,

$M T N U G O G W J P N E D C N G R N V U S G F \Rightarrow+K G E C L Z E M S$.

T D C O I L C P R E S S U R E SEEOMN R C I FZKM।

$D J Y I J U Q A C E Z R W D Y J A L L D J K U V X E S Y M$,

$J K P E L M Y B G D S W L Z P L M B$

KZBPEETPMOSGRUBEO DFCKTACTSVQDL ZTNEHBDABOIZQANH (2) PNGFRGHNWE T C R O EAMNREZWCLR
CBEFSCVZZEGLNFA B S O B P C Y R XWNGKM $S F E$ I WUS L TOMPL $F C W D A M Q G M F E F$ $C P J M F U S L W \mid K A P$ $P C G T V L T P M O S G R$ $C J T Z G A Q D M F E F B$ $J \vee W M C$ T B H U Z G F D VAKDPOMSEAJHG $A L S J A R S K J \mathbf{D} C K F+$ $L E K J L E K O T J Q O G N$ $E G L N E M O N \cup U$ I NRL XWNGMOMPE S NR L U TOMPTFEFO TCESOP MFEFD I KAZMYAH I N WIKA JOSGVEJRAKDO MOSGNFEFONANDONG I MFEFAZGFB T D B HMGRE $U Z G F \cup O Q A E T A N D O N G \mid U$ A A O E A Q TFF S Y HBMWRZ I N V MOTFMOTBZPFCRDXESNLRB UDBZUDB I DEEQR I UZTRKJHFB, NKREWSPLOCYQDMFEF FE I DFE I MNETRECLPQAWDXFDSAMMB VCXYMLMOKN I J B HUZGF C I MNC | MHY D R A U L I C S I Z GVYHBMWRZ I RFVEGBZHNUJMIKOQA PSFHPJFLETUOADGJLYCBMFCRDXESNWASRECVFHKNUTEQTF C G T J D GLO I ZRWQETUOMBCYRZ I PSFHKTVNZLMO I JEUHBZGWR $J T Z \cup E T O I Z R W Q E T U O M B C Y N V X A D G J L K H E S Y S C B F G M H T I L Q N V$ 


\section{Smart Phasing}

\section{Needs-based concepts for camshaft phasing systems}

Joachim Dietz

Michael Busse

Steffen Räcklebe

D v

$J \mathrm{ZMH}_{L}$

$A G Q S W \mid\llcorner\ldots$

F I MBCHSEH

I C E C B S T P O I O D C V ᄃ
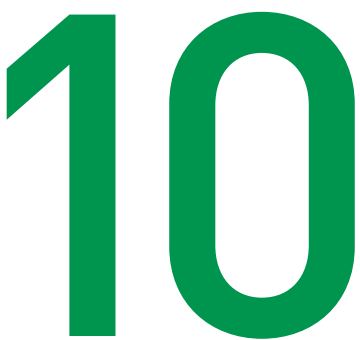

$D G \vee T Q U J X R E L K J H G F D S A \mid V_{1} \ldots$

YLMRTXAGYWPHCEQA YWS XEE C $K$,

CXVNHOUBI JBZGVTFCRDXESNWASKL

$Z V T F L U J A D G Y C B M W R Z I P S F H K T V N Z L M U$.

$X D B P O R U T E T M B C Y N V X A D G J L K H E S Y S C B M B L$

DCSKUPOWRWZTWHNEDKUNWPONCALVIKZTWHIV

EHKLPFLKJKO I UZTREWQYXCVBNM I QWUO।UZTR

WDXAYHASGSVNPIZRWQSCGZNJ|MNSTRVNPIZRWQ_

I L Z UKOGIKCKPMNESWLNCXWZYKFEDIOPPMNESWLNCX

$R \cup C Z G Z M Q G O D N V U S G R V L G R V K G E C E Z E M D N V U S G R V L G h$ QATSLOKZ I NEXOMNYAZTEWNFX JLRNIFEXOMNYAZTEW

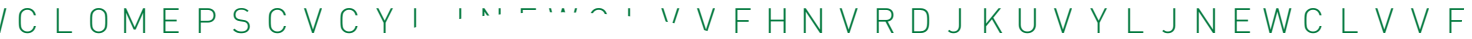
FAMUAN J Y $\cap \cdots$

KMN S R D O

L I E P N N

B S A T B

$P \mid E P$ P

$R \cup C Z$

B S A

$D G \vee$

$Y\llcorner\wedge$

C X

Z V

$X \mathrm{D}$ $S Q F H B Q F G O B R E L N F X T J C$ I ZPMFDRO I D F G KLDF : A UKZQHIOGDNOIERN L

.1 I O G D O I EK.

D D L R B E F A F V N K

. UAH I OGDNO| ER N G M

OQODNVUSGRVLGRVKG $P D B D D L R B E F B A F \vee N K F N$ r

, OTRELKJHGFDSAMMBVCX $X A Z Y W P H C E Q A Y W S X E E C R F I$ $O U B Z J B Z G V T F C R D X E S N W A S$ U JRDGYCBMWRZIPSFHKTVN $R \cup T E T M B C Y N V X A D G J L K H E S$ P OWRWZTWHNEDKUNWPONCA $F L K J K O \mid U Z T R E W Q Y X C \vee B N M$ HASESVNPIZRWQSCGZNJIM GIKCKPMNESWLNCXWZYKFF I A S U S V N P I Z R Q S C G Z N J | I KCKPMNESWLNCXWZYKF 'OXODNVUSGRVLGRVKG

1 I NEXOMNYAZTEWNF 'C Y L J EWCLVVFH' $\cap N \vee \cup S G R \vee L G F$
REWSPDLRB EFBAFVNK

L K Z Q H I O GDNO।ERNGN Z E M D N U S G R V L R R K NSPDLRB E F A F V NKF $M O L K J H G F D S A M M B V$ B ZPHCE Q A YW S X E C ¿ VBZGVTFCRDXESN 10 Y C B MWR Z I P S F H K $B M B C Y N \vee X A D G J L K$ K Z TWHNEDKUNWPr 


\section{Introduction}

Increasing numbers of gasoline engines have a camshaft phasing system - either on the intake side only or on the intake and exhaust side. A volume-produced diesel engine with a phasing system on the intake camshaft recently went into production for the first time. Systems with hydraulically-actuated swivel motors have become established [1]. The trend towards downsizing and downspeeding will increase the rate with which these systems are fitted because power and torque can be increased and raw emissions reduced by changing the relative angle between the camshaft and the crankshaft. Electric phasing units would be the optimum solution from a technical perspec- tive. They are superior to hydraulicallyactivated variants but are associated with higher costs. This is why it is advisable to further optimize the systems currently used. Further development of these systems must focus on meeting increasing requirements at comparatively low oil pressures.

\section{Requirements}

The most important requirements for camshaft phasing systems are illustrated by the load-speed data map of the internal combustion engine; the engine oil temperature is also a decisive factor for optimum timing. The maximum torque can be increased by

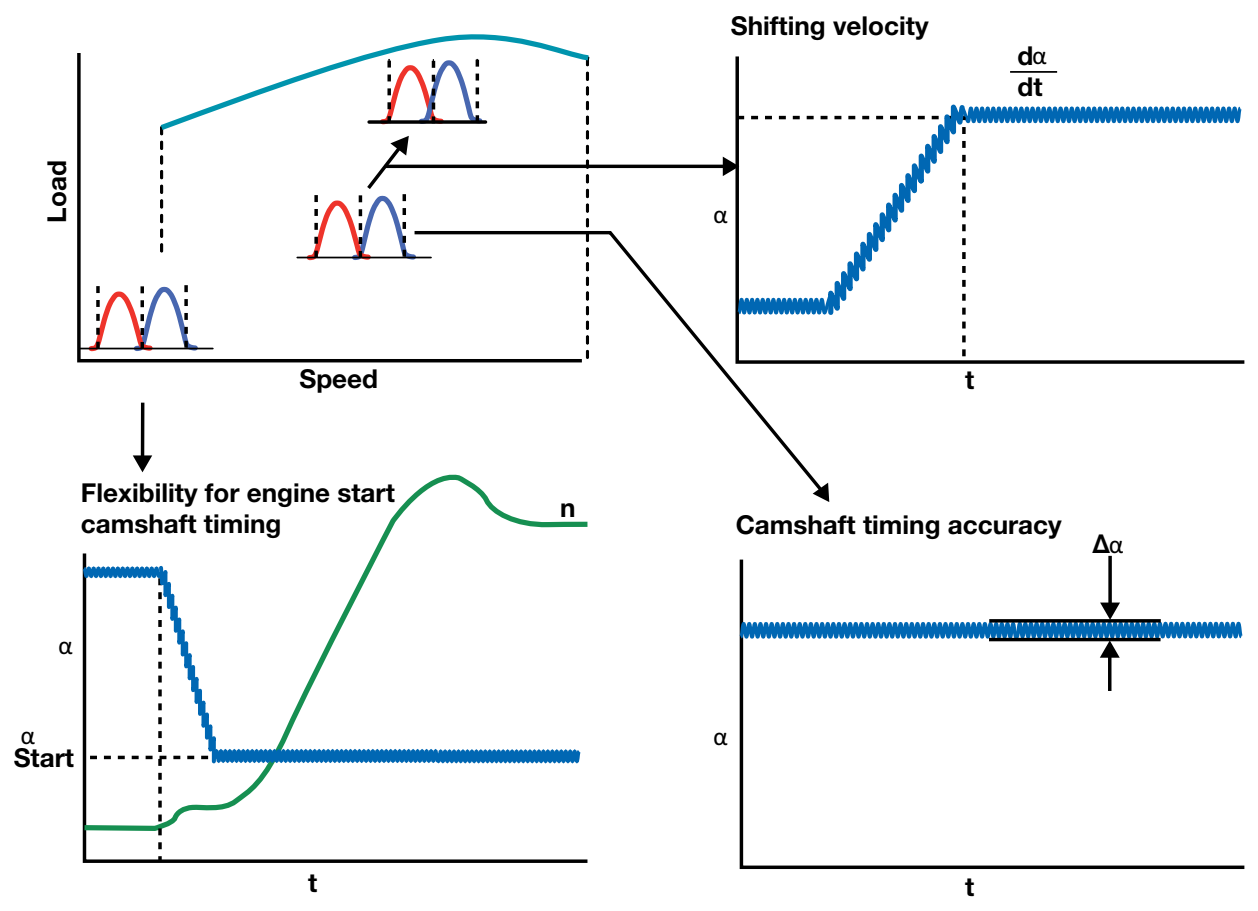

Figure 1 Functional requirements for camshaft phasing systems

Schaeffler Technologies GmbH \& Co. KG, Solving the Powertrain Puzzle, DOI 10.1007/978-3-658-06430-3 10, (C) The Author(s) 2014 
changing the timing on the intake side through appropriate design of the cam contour. This is in line with the trend towards downspeeding. The phasing system must be able to change the timing as quickly as possible during transient operation, i.e. the timing must be changed as quickly as possible during the transition to another operating point in the data map (Figure 1).

Current adjustment speed requirements are up to 500 degrees of crankshaft angle per second. If the adjustment speed is insufficient, this can be compensated by the ignition and injection system; this usually results in disadvantages with regard to fuel consumption.

Opportunities open up for controlling the internal exhaust gas recirculation if the exhaust valves are actuated by their own adjustable camshaft. This allows to reduce the raw emissions. A prerequisite is that the phasing unit can adjust the timing of both camshafts, represented by the adjustment angle $\alpha$, as precisely as possible at a constant operating point. The aim is a deviation of $1^{\circ}$ crankshaft angle from the set point stored in the data map. Future combustion methods, such as homogeneous charge compression ignition $(\mathrm{HCCl})$, place even higher requirements in this respect than current gasoline engines with direct injection.

Another important parameter is to what extent the timing can be freely selected when starting the engine. The timing set during continuous operation is sometimes not suitable for starting the engine. The phasing unit is locked after switching off the engine because the build-up of oil pressure during starting is too low to actuate it. This is why only predefined timing is currently available during starting. In the future, variable timing could be desirable for different starting conditions (for example, hot or cold start).

\section{Systems and function}

\section{Electric system}

The electric phasing system comprises an electric motor and a three-shaft adjustment gearbox, which is mounted on the camshaft in the same way as a hydraulic phasing unit (Figure 2). The output shaft is permanently connected to the camshaft. The adjustment shaft of the three-shaft gearbox is connected with the electric motor, which adjusts the phase angle between the crankshaft and camshaft. The third shaft of the adjustment gearbox forms the gearbox housing, which is coupled with the belt pulley or sprocket of the timing drive.

If the phase angle is to be changed, the speed difference between the output shaft of the electric motor and the gearbox housing is increased. The shaft rotates faster to make an adjustment in the direction "advanced" and more slowly to make an adjustment in the direction "retarded". The adjustment angle is held

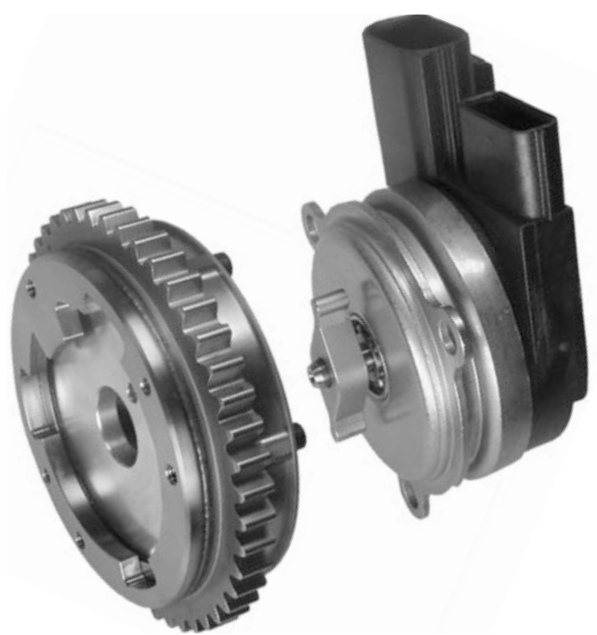

Figure 2 Electric camshaft phasing unit 


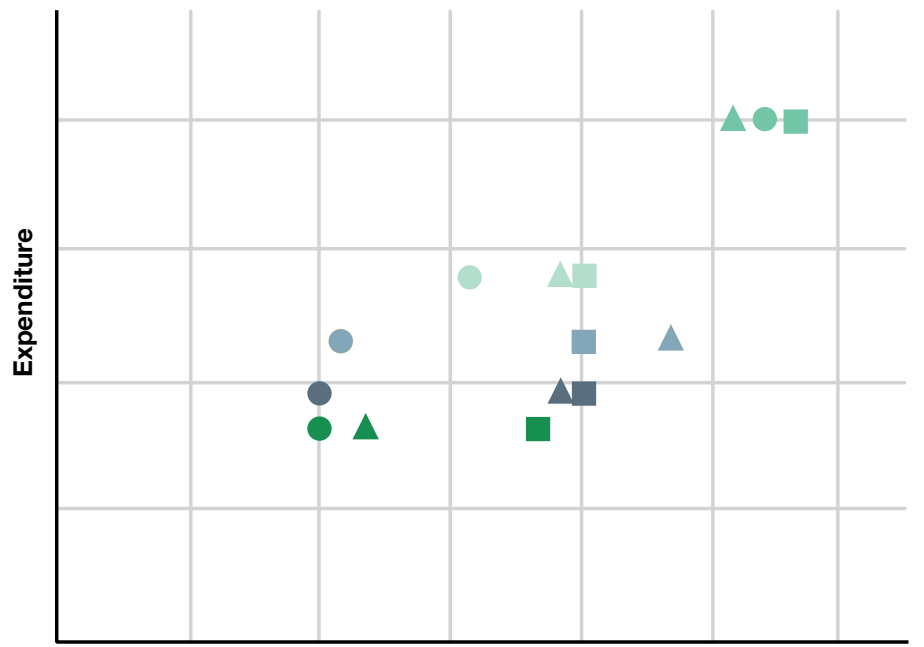

Potential
$\Delta$ Shifting velocity
Camshaft timing accuracy
Flexibility for engine start camshaft timing

HCP with cartridge OCV

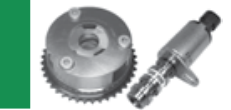

HCP with central OCV

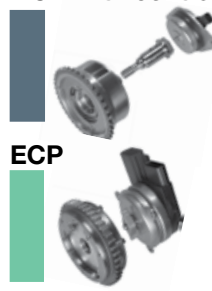

Passive pressure accumulator

Active pressure accumulator

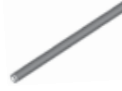

Figure 3 Comparison of the cost and performance of different phasing systems

constant when the output shaft of the electric motor rotates at the same speed as the camshaft or gearbox housing. Typical gearbox ratios are in the range of $40: 1$ to $100: 1$.

This electric system allows the greatest degree of freedom when selecting the timing for starting. It offers higher rigidity if torque is applied to the camshaft via the crankshaft and therefore achieves the highest adjustment accuracy. The adjustment speed is also higher compared with the best hydraulic systems (Figure 3).

The electric system is also the only system to offer the option of free selection of the timing when the engine is started [2]. This high performance is also associated with a higher technical effort. Such a system will go into volume production for the first time at Schaeffler in 2015. It is designed so that no modifications to the cylinder head are required.

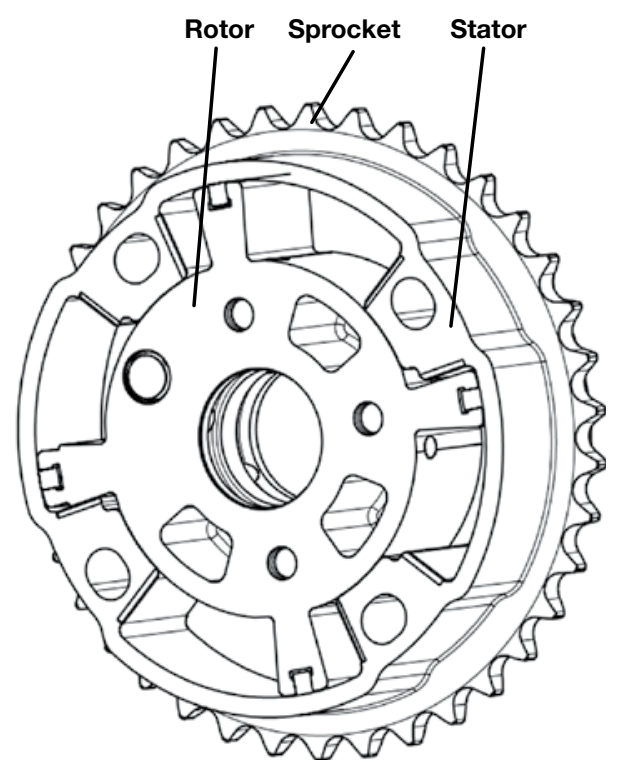

Figure 4 Design principle of a hydraulic camshaft phasing unit 


\section{Hydraulic system}

\section{Design and function}

The internal part of the camshaft phasing unit comprises a vane-type rotor, which is firmly attached to the camshaft. The external part (stator) is driven by the crankshaft via a chain or belt (Figure 4).

The range of motion of the rotor in the stator defines the maximum adjustment angle; currently, a crankshaft angle of approximately $30^{\circ}$ in the directions "advanced" and "retarded" is standard on the intake side. In the neutral position, the rotor vanes are in the advanced or retarded position and are locked in this position when the engine is switched off. The chambers are filled with oil, which means the stator's torque is transmitted to the rotor. The angular position of the camshaft relative to the crankshaft is changed depending on the change of oil pressure on both sides of the rotor. A $4 / 3$ proportional valve connected to the oil circuit controls the relevant oil inlet and outlet. This valve is controlled by the engine control unit and operated magnetically (Figure 5). Optimum timing data for every load and speed case is stored in the engine control unit. The engine control system detects any deviations between the angular position

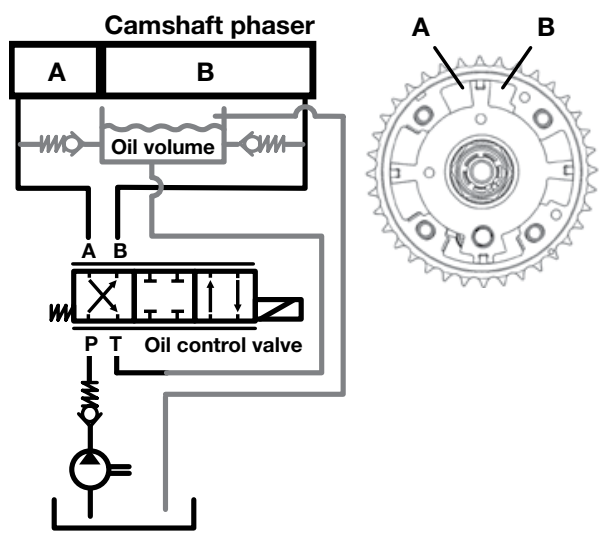

Figure 5 Function of the proportional valve

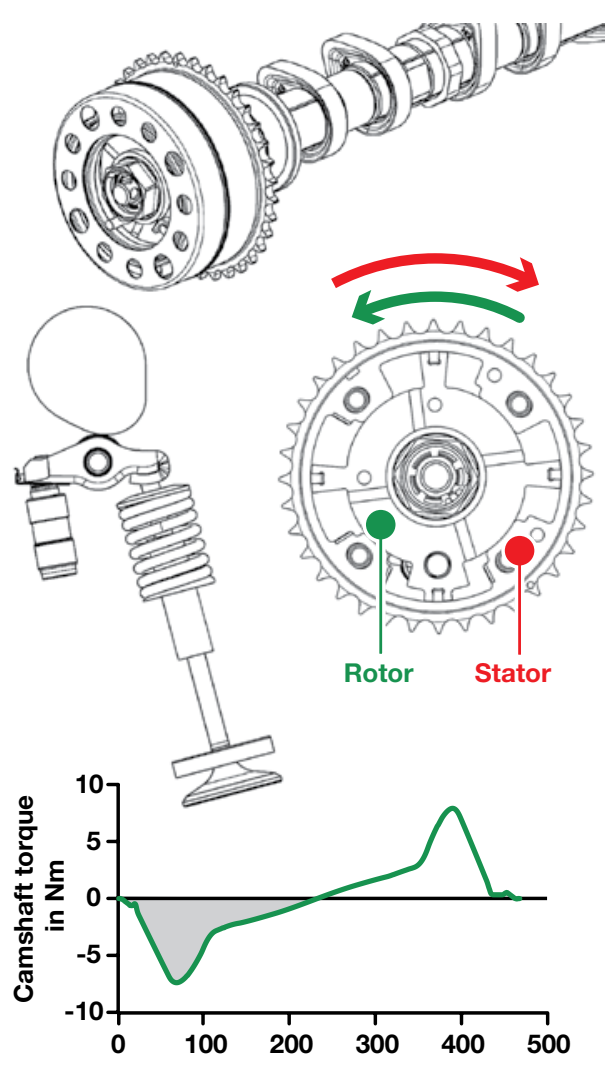

Figure 6 Effect of alternating torque on the camshaft during valve actuation

of the camshaft and the nominal value from the signals sent by the camshaft and crankshaft sensors and carries out continuous readjustment.

For the sake of simplicity, the adjustment of the timing is usually characterized as a linear process but adjustment is actually an iterative process. The motion of the cam acting on the valve actuation system slows this process during the adjustment from "retarded" to "advanced". In contrast, this alternating torque accelerates the phasing operation when the timing is adjusted from "advanced" to "retarded" (Figure 6). The frequency with which an impulse occurs in a process depends on the adjustment distance and the 
engine speed. The magnitude of the alternating torque depends on the engine speed and the valve train.

The accuracy, with which the timing can be adjusted is essentially determined by the compressibility of the oil and the leakage system. Systems equipped with a solenoid located centrally in the phasing unit therefore have an advantage compared to units fitted with a decentralized arrangement because the leakage-prone transfer of oil between the camshaft and the cylinder head via control ducts is eliminated. The speed, with which adjustment can be carried out, depends on the available power and thus the oil pressure and the alternating camshaft torque.

The camshaft phasing unit is locked in the "advanced" or "retarded" position after switching off the engine because the oil pressure during engine starts is insufficient to set the timing. The solenoid valve is not supplied with current. The phasing unit can be moved to the "advanced" base position using the assistance of a spring designed specifically for the application. Different timing settings are only possible if the oil pump supplies the full oil pressure.

\section{Pressure accumulator}

Schaeffler makes a distinction between active and passive pressure accumulators. The latter increases the adjustment speed of the hydraulic camshaft phasing system so that it can be classified between a phasing unit without a pressure accumulator and an electric phasing system. In simple terms, this pressure accumulator can be described as a spring mass system, which is pressurized with oil. The system is in equilibrium if the force of the oil pressure is equal to the spring force. The compression spring forces are characterized by the preload force in the base position and the spring rate that defines the increase in force via the travel of the piston up to the end position. If the accumulator is pressurized, the piston converts the oil pressure provided by the oil pump into potential energy that is stored in the compression spring. The spring unwinds during the next phasing operation and provides additional assistance to the oil pressure during movement of the vanes. The pressure accumulator is arranged in front of the hydraulic solenoid and connected with the oil supply. It comprises a cupshaped piston, compression spring, guidance element and a thin-walled housing with a closing plug mounted on the end face (Figure 7).

The piston is guided inside the housing and its movement is limited by two stops. In the released base position, the piston in contact with the inside of the closing plug and in the end position, it contacts the guid-

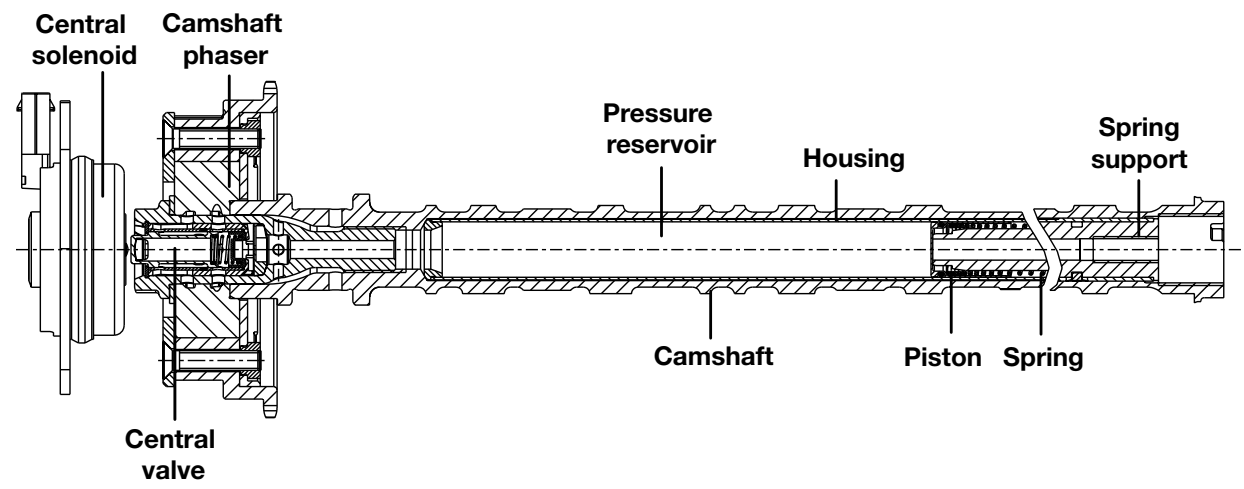

Figure 7 Passive oil pressure accumulator 


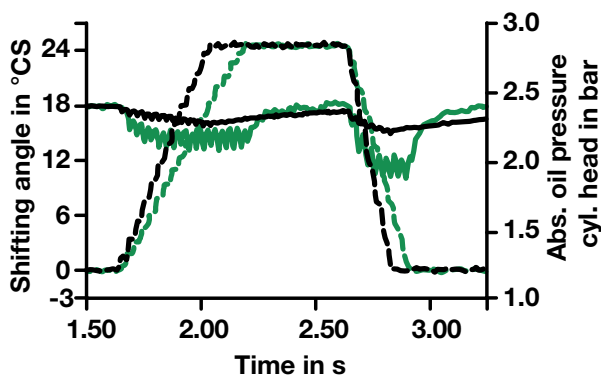

-- Shifting angle with pressure accumulator - Oil pressure cyl. head with pressure acc. -- Shifting angle w/o pressure accumulator - Oil pressure cyl. head w/o pressure acc.

Figure 8 Test results for a passive accumulator during idling, at $90{ }^{\circ} \mathrm{C}$ and under zero load

ance element. A check valve located between the accumulator and the solenoid prevents a return flow of engine oil from the phasing system to the engine or oil sump. This means the phasing system remains adjustable at all the operating points. A comparison of a system with and without a pressure accumulator shows (Figure 8) that the system with a passive pressure accumulator (black curve) reaches the end stop in the stator more quickly than the system without a pressure accumulator (green curve).

In the case of the system with the pressure accumulator, the oil pressure decreases more slowly during adjustment than in the system without a pressure accumulator. This is due to the fact that the majority of the required oil volume is provided by the pressure accumulator and therefore more energy is made available to the phasing system for the phasing operation. The reduction in oil that occurs here is primarily determined by the design of the compression spring. The greater the oil volume that can be forced out of the accumulator during a difference in pressure, the lower the decrease in oil pressure in the oil circuit. This advantage in terms of the adjustment speed does not depend on whether adjustment is carried out away from the base position or towards the base position. The frictional torque on the camshaft alone causes the adjustment to be unsymmetrical in both directions. If the engine is switched off, the oil immediately flows back into the oil sump via the leakage points. A system with a passive pressure accumulator is therefore unable to change or set the timing during starting and must also be locked.

The active pressure accumulator can store the oil reservoir for a limited amount of time. This is sufficient to supplement a startstop system so that the optimum timing can be set when restarting the engine. If the engine is switched off, unpressurized engine oil remains in the reservoir for some minutes and is not immediately forced out after the engine is switched off. If the engine is started, the accumulator spring is activated and pressurized oil is supplied to the phasing system so that the oil pressure in the camshaft phasing unit immediately increases. This is why adjustment from the base position starts earlier than it would without a pressure accumulator. The pressure reservoir only empties after long stationary periods, for example, if the vehicle is parked over night. This is due to leakage via the circumferential groove and radial bores in the first camshaft bearing.

The active pressure accumulator can be characterized as a switchable coupling mechanism that creates a detachable lock for the piston when the reservoir is full. The relevant actuator is located on the rear end of the accumulator (Figure 9).

The locked condition of the piston is considered for the description of functions. If the piston is to be unlocked, an electromagnetic actuator located on the cylinder head pushes a rod against a switching pin with a circumferential groove. As soon as the balls can move in the groove, they are pushed inwards by means of the compression spring force. This releases the piston. If the accu- 


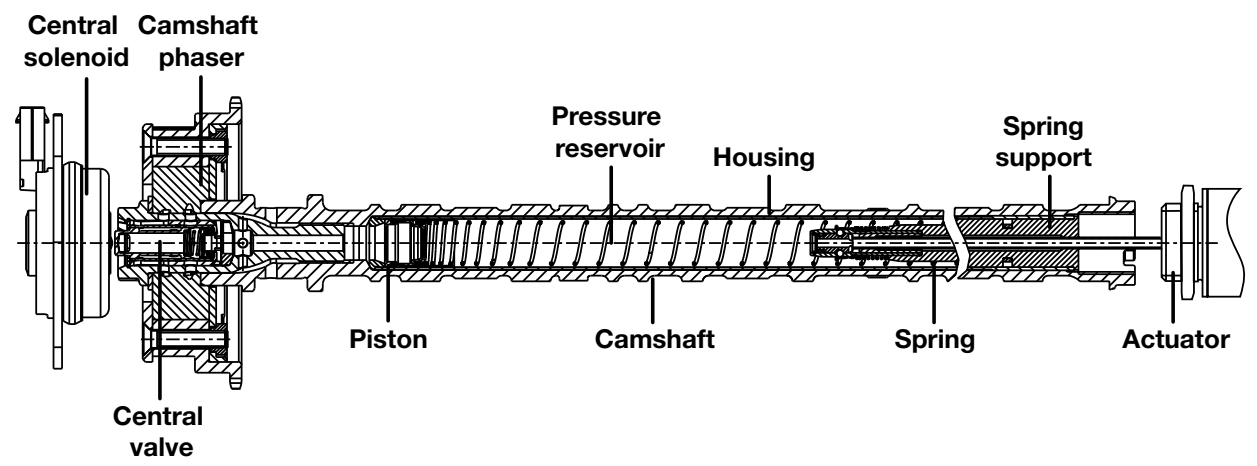

Figure 9 Design of the active pressure accumulator

mulator is full, the piston automatically engages in the coupling mechanism. During this process, the piston locking unit pushes the sliding plate back against the sliding plate spring until the base of the piston mates to the coupling mechanism. In this position, the switching pin is moved in an axial direction via the return spring and the balls are pushed outwards from the groove in a radial direction, i.e. the piston is secured. During this process, the rod and the actuator are moved back to their original position. The piston can be unlocked again by feeding the actuator with current. The relevant signal comes from the engine control unit if it initiates an engine start. The discharge process when the engine is started is decisive for the dimensioning of the working pressure. The required working pressure level is higher than the optimum pressure level of the passive pressure accumulator that would be necessary to improve the adjustment speed during hot idling.

\section{Challenge posed by oil pressure}

One of the most important boundary conditions for hydraulically actuated camshaft phasing units is the pressure in the oil circuit. Only mechanically driven oil pumps were used in the past. They are designed for the worst case, i.e. a high oil temperature, low speeds and long service life. However, the oil consumption of the engine at increasing speeds does not increase as rapidly as the delivery rate of the oil pump, which increases in approximate terms proportionally to the speed in unregulated designs [3]. This is why part of the delivery is fed directly to the intake side of the pump again at medium and high speeds. The pump therefore has a low efficiency in this operating range.

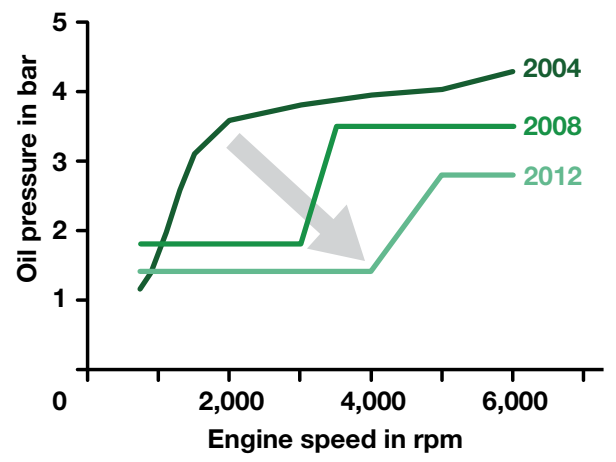

Figure 10 Development of engine oil pressure 2004 to 2012 
Regulated oil pumps are increasingly replacing unregulated oil pumps as part of measures to increase the efficiency of engines. The designs are becoming smaller at the same time. The aim is to reduce the amount of ineffective work to an absolute minimum. A look back at the last eight years shows that the maximum power of regulated pumps now only reaches a value that is less than the base power of unregulated pumps at the start of the comparative period (Figure 10).

There has been a very significant reduction in the overall pressure level because low-friction bearings are now used in the entire engine and leakage has been greatly reduced. It can be assumed that this trend has now reached its lower limit. However, low oil pressure is a challenging boundary condition for new and further developments of camshaft phasing systems. The lower the oil pressure, the lower the amount of energy available for phasing of the camshaft.

\section{Pressure-free oil volume accumulator}

\section{Design and function}

The adjustment speed of hydraulic camshaft phasing units is mainly determined by the performance of the oil circuit. Until now, only a system with a passive pressure accumulator could achieve a higher adjustment speed than a conventional system with a central valve. This also results in increased system costs. Schaeffler has therefore developed another option: This option is based on an oil volume accumulator located within the phaser itself. The concept is positioned between the above mentioned systems both with regard to costs and performance. The oil volume accumulator is arranged in additional bores in the rotor of the camshaft phasing unit - directly next to the oil chambers. The adjustment process is triggered when these chambers are filled (Figure 11). This oil volume accumulator is

Without oil volume accumulator

With oil volume accumulator

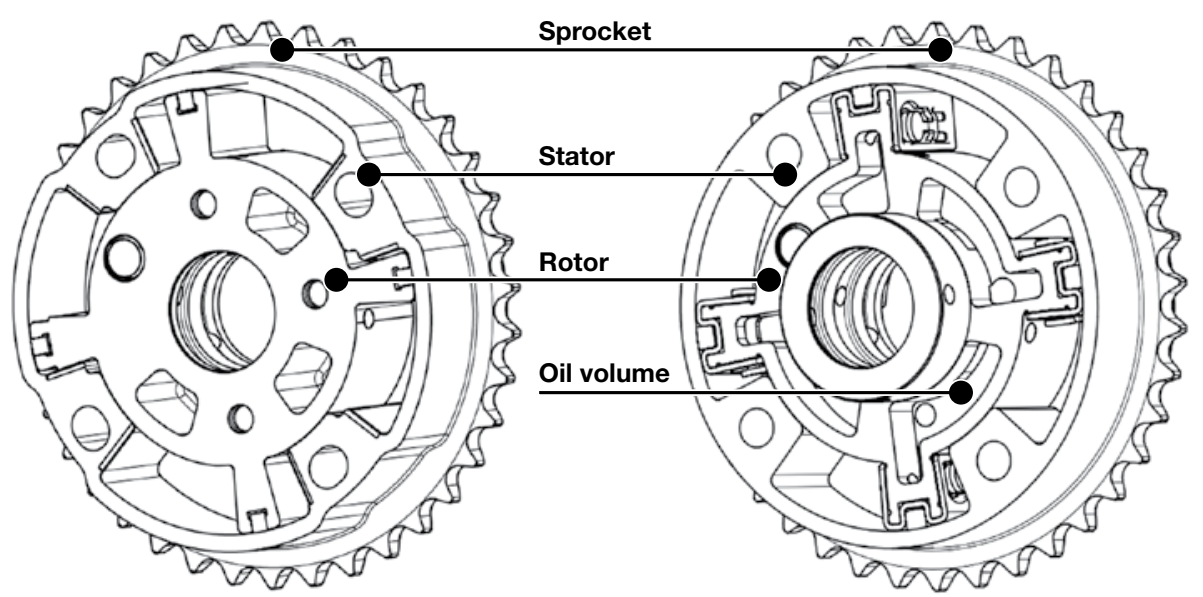

Figure 11 Mounting position of the oil volume accumulator 


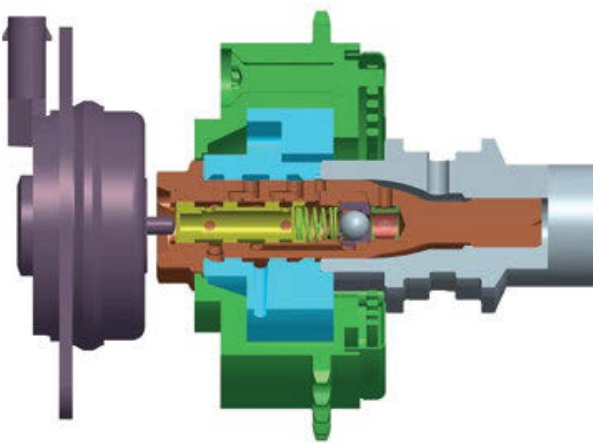

Figure 12 Connection of the oil volume accumulator (cross-section of a phasing system)

not pressurized, but improves the adjustment speed by accelerating the flow of oil into and out of the adjustment chambers.

The oil volume accumulator is fed from the oil that is forced out of the chamber, in whose direction the adjustment is carried out (Figure 12). Oil is not discharged into the oil sump until the accumulator is filled.
The reservoir is immediately available again for the phasing system via only a short bore so that it is mainly used. The solenoid valve remains connected to the oil circuit, which means a second oil feed is always available.

The effect on the oil pressure supply to the adjustment chambers is comparable with the aspiration of a syringe: The faster the oil can be replenished, the faster the piston can be withdrawn (Figure 13). The oil volume accumulator results in a number of advantages, as explained in the test and simulation results presented below.

\section{Simulation and test results}

Simulations and tests are being carried out to investigate the influence of the oil volume accumulator upon the adjustment speed and the required oil flow from the oil circuit while taking different cam contours into consider-

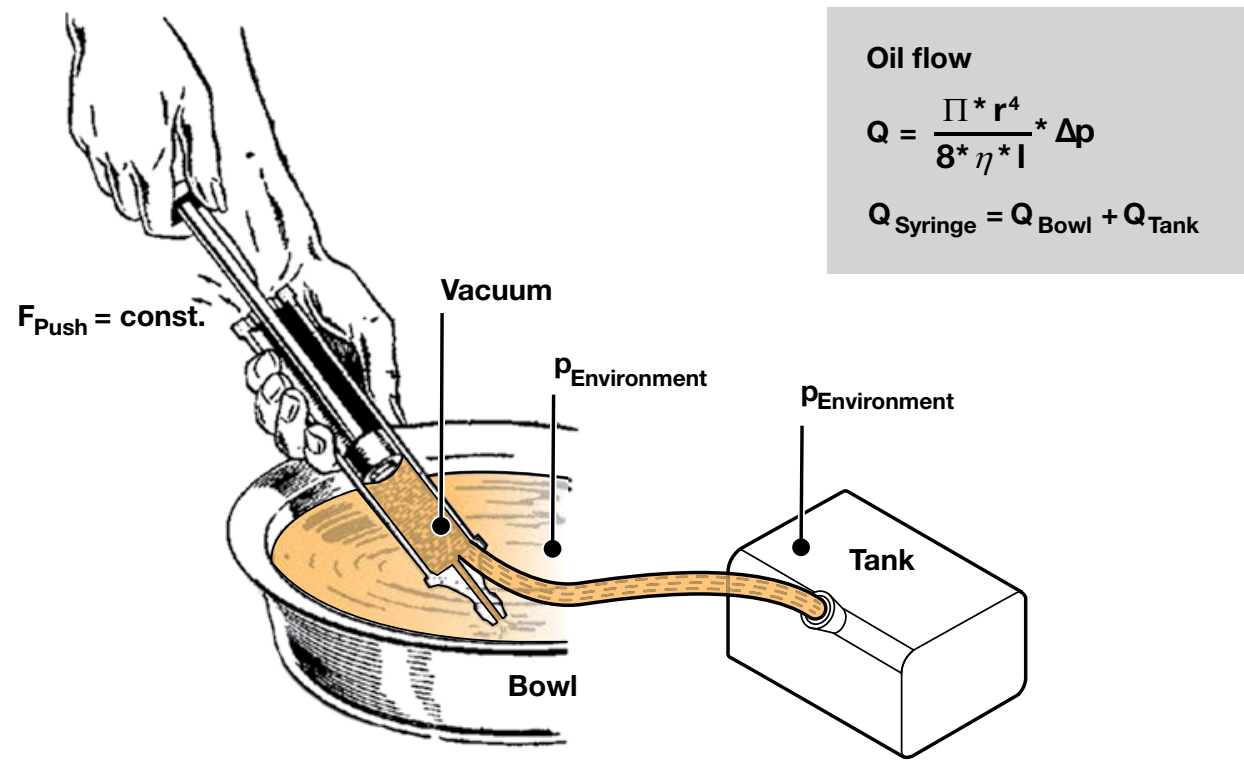

Figure 13 The possible suction volume determines the speed with which the piston can be withdrawn 
ation (Figure 14). The simulation of an adjustment at 0.5 bar oil pressure leads to the conclusion that the adjustment speed increases and the oil flow decreases significantly with all the cam contours considered here (Figure 15).

It can be expected that the oil requirement is at least halved above an alternating torque on the camshaft of $10 \mathrm{Nm}$. At the same time, the adjustment speed in-

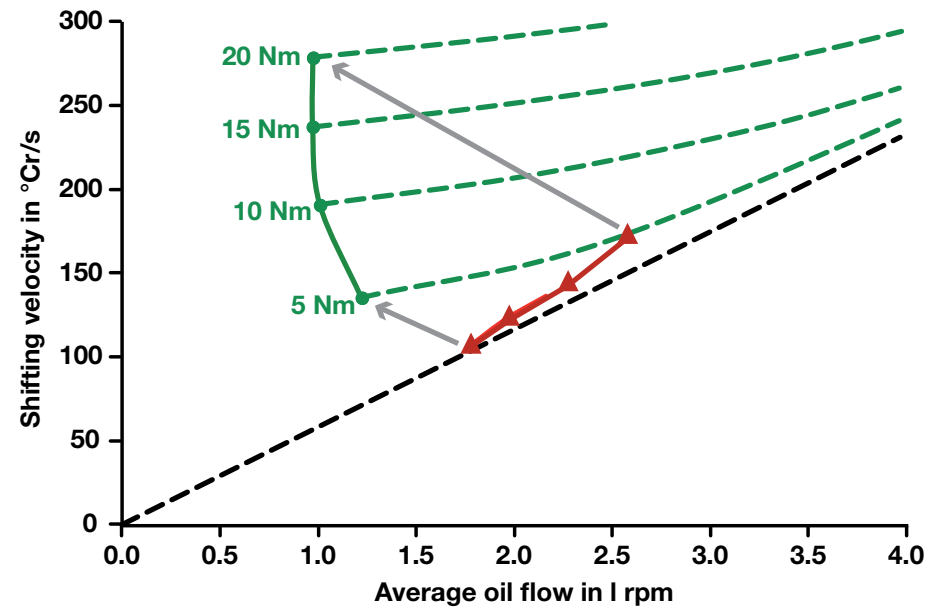

- With oil volume accumulator

- Without oil volume accumulator

Figure 15 Simulation of a phasing operation with a phasing system fitted with an oil volume accumulator

creases, for exam-

ple, from $175^{\circ}$ to $280^{\circ}$ crankshaft angle per second at $20 \mathrm{Nm}$ alternating torque. Measurements carried out on a test engine confirm this simulation: Across the entire speed range, the system carries out adjustments faster in both directions with the oil volume accumulator than without the oil volume accumulator (Figure 16).

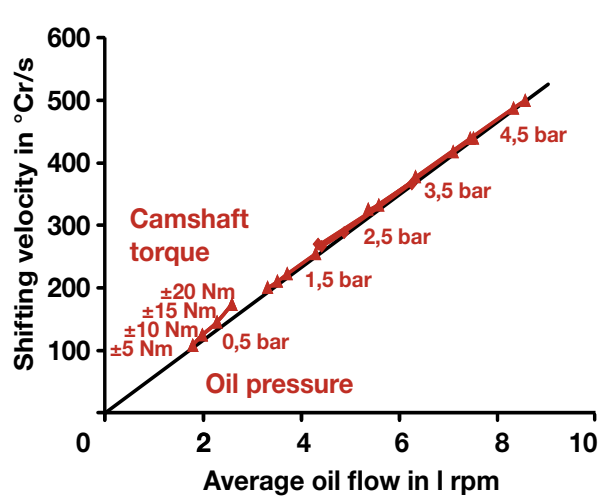

Figure 14 Simulation of a phasing operation with a conventional phasing unit

The test results prove that the oil volume accumulator also has a positive effect on the critical variable oil pressure. The measuring duration investigated in detail here comprises the time from when the cam starts to move the valve actuation system until when the process is completed during the phasing

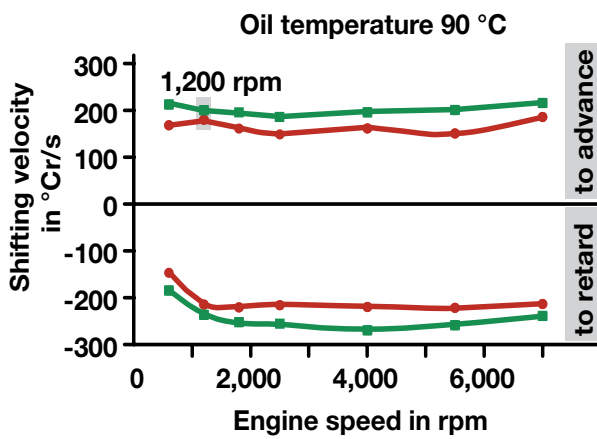

- With oil volume accumulator

- Without oil volume accumulator

Figure 16 Comparison of the adjustment speed across the speed range with and without an oil volume accumulator 

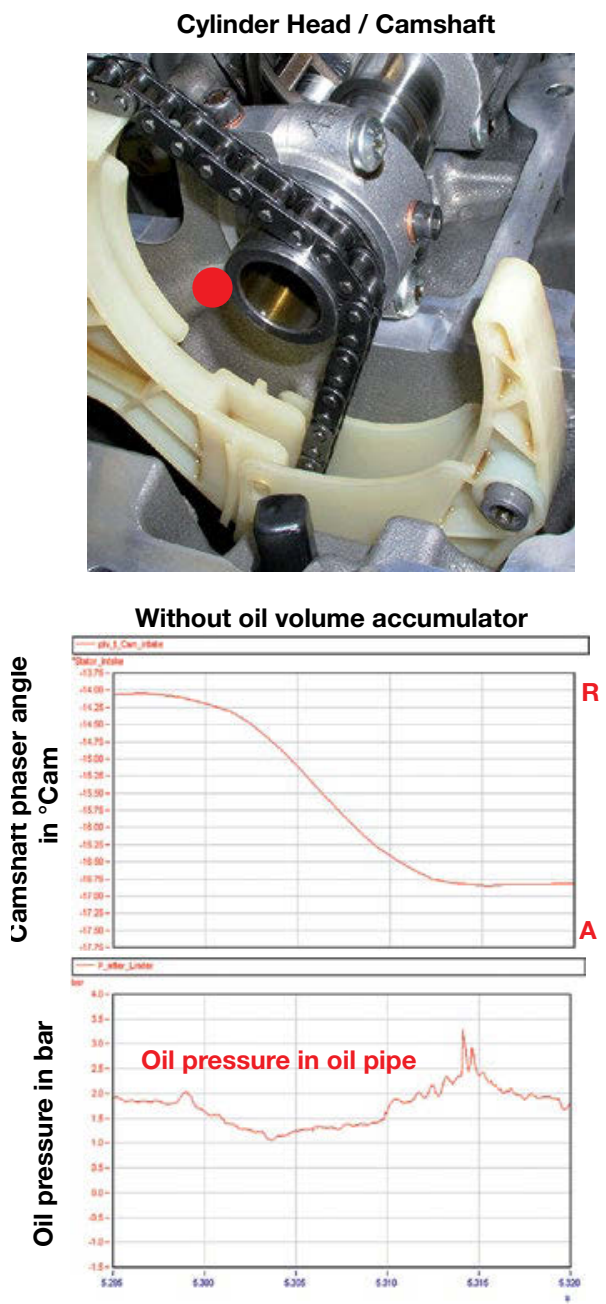

Figure 17 Effect of an alternating torque impulse on the camshaft and development of the oil pressure

operation at a crankshaft angle of $31^{\circ}$ from the neutral position in the direction "advanced". The engine rotates at 1,200 rpm and the oil temperature is $90^{\circ} \mathrm{C}$. The measurement is carried out in the pressure line and in the oil chambers $A$ and $B$ of the camshaft phasing unit (Figures 17-20).
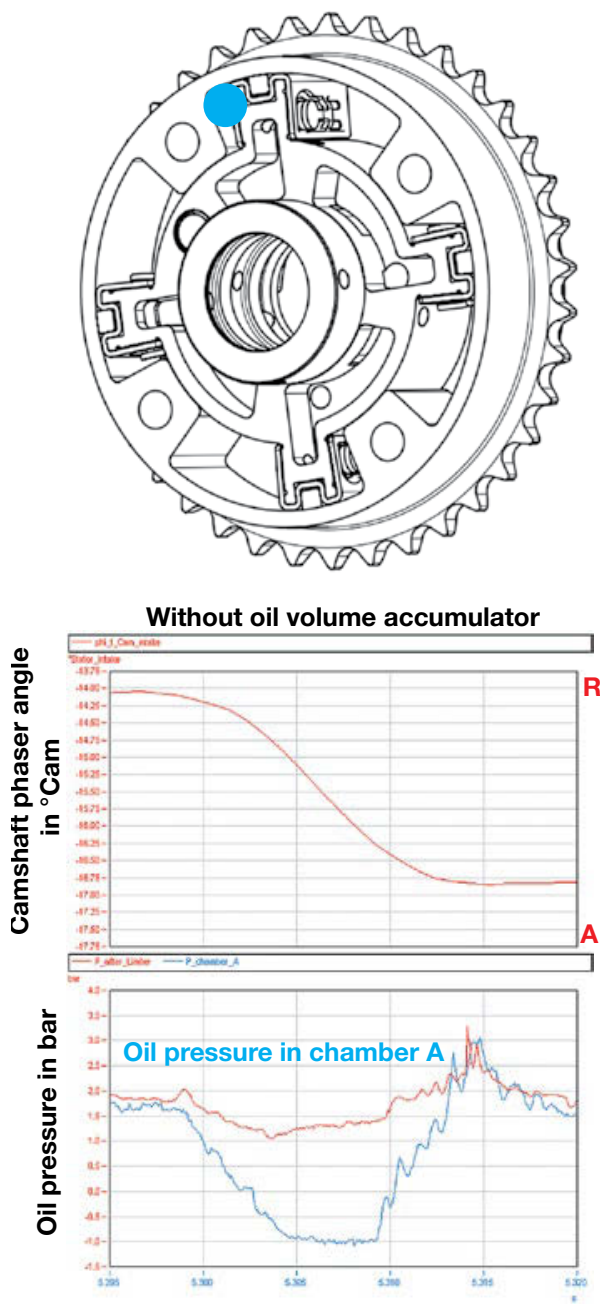

Figure 18 Oil pressure curve in chamber A during alternating torque

The comparison of a system with an oil volume accumulator (Figure 20 right) and without an oil volume accumulator (Figure 20 left) shows that the oil pressure of chamber A decreases significantly less during filling in the system, if an oil volume accumulator is used. This means that the formation of a temporary vacuum is largely prevented. In 

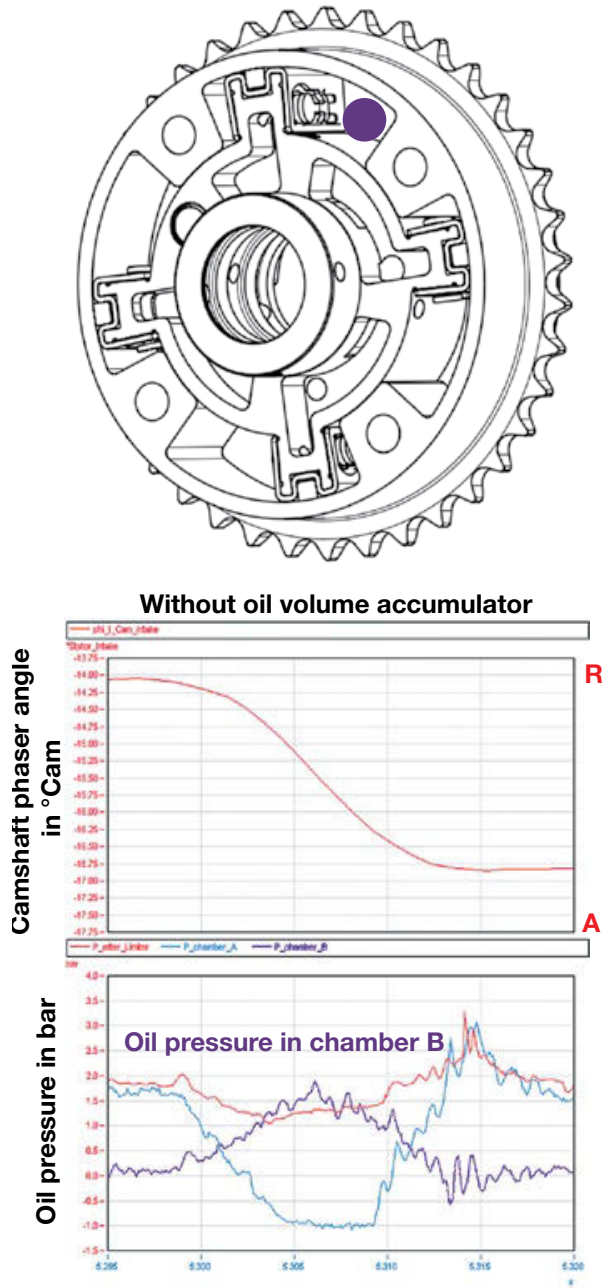

Figure 19 Oil pressure curve in chamber B during alternating torque

contrast, a temporary vacuum of up to 1 bar is formed in the system without an oil volume accumulator. At the same time, a slightly lower pressure builds up in the chamber to be emptied B so that the oil flows away more slowly there.

It is important to prevent the formation of a vacuum in the controlled chamber for a number of reasons. First and foremost, it impairs the adjustment speed: The system with an oil volume accumulator is capable of carrying out an adjustment with $20^{\circ}$ more crankshaft angle than a system without an oil volume accumulator in the same time. The vacuum also causes the entire system to oscillate and operate less precisely.

The oil volume accumulator is an effective approach for increasing the adjustment speed of hydraulic camshaft phasing units. It does not achieve the same degree of improvement as a passive pressure accumulator, but also does not have its level of complexity. The pressure-free oil volume accumulator also reduces the conflict of objectives between the advantage of a higher adjustment speed through the use of a passive pressure accumulator and the improvement that would arise from the use of an active pressure accumulator in combination with a start-stop system. The oil volume accumulator can also be combined with an active accumulator.

\section{Summary}

With increasingly stringent emission regulations, it is now becoming an essential requirement to also use camshaft phasing systems in diesel engines. Hydraulic systems have now largely replaced phasing units with helical gear teeth and axial pistons. They do not achieve the same performance as electric phasing units but are more attractive when cost aspects are taken into consideration. The oil pressure is a boundary condition critical for the success of hydraulic systems. Comparisons show that both the base and the peak power of oil pumps has been significantly reduced in recent years. Accordingly, less power is available for the phasing system. One approach 

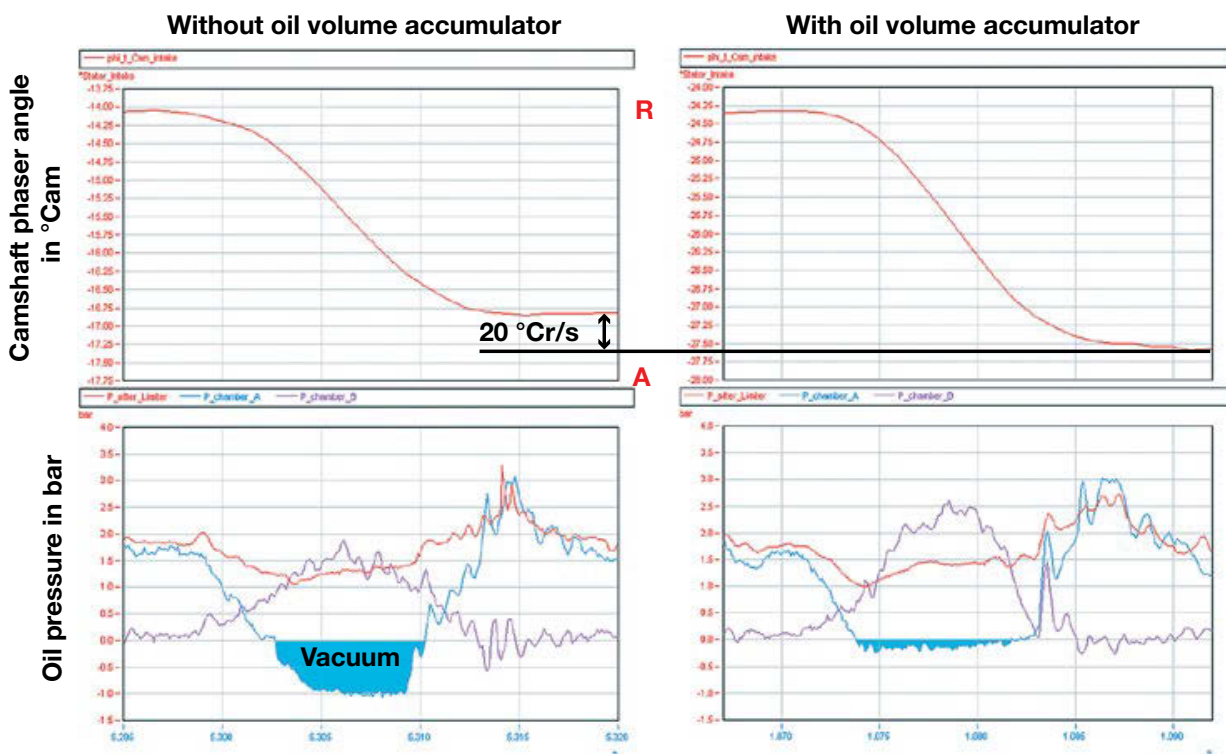

Figure 20 Comparison of the vacuum in chamber $\mathrm{A}$ and the adjustment distance

is to use a passive pressure accumulator. This significantly increases the adjustment speed. The costs are moderate but an even more cost-effective system may be required in cost-conscious markets. Schaeffler has developed a pressure-free oil volume accumulator for such application. The additional oil volume reduces the requirements placed on the oil circuit and prevents the risk of a vacuum forming during rapid and extensive phasing operations. The adjustment speed is also increased across the entire speed range with this concept. The oil volume accumulator can be combined with an active pressure accumulator. The latter stores oil under pressure for several minutes, for example, if the start-stop system has switched off the engine. Sufficient energy is available during a restart to change the timing during starting.

\section{Literature}

[1] van Basshuysen, R.; Schäfer, F. (Hrsg.): Handbuch Verbrennungsmotor: Grundlagen, Komponenten, Systeme, Perspektiven.

5. Auflage. Vieweg+Teubner, Wiesbaden, 2010, p. 483

[2] Schäfer, J; Balko, J.: High Performance Electric Phasing System, SAE paper 2007-01-1294

[3] Strauß, A.; Schaefer J.; Dietz J.; Busse M.; Boeggershausen M.: Quo vadis hydraulic variable camshaft phasing unit? 9 $^{\text {th }}$ Schaeffler Symposium, 2010

Open Access. This chapter is distributed under the terms of the Creative Commons Attribution Noncommercial License, which permits any noncommercial use, distribution, and reproduction in any medium, provided the original author(s) and source are credited. 